\title{
Risk adjustment - never enough or too much?
}

J. Nicholl

Qualitätsmanagement

Keywords

risk adjustment

hospital comparisons

Constant risk fallacy

Schlüsselwörter

Risikoadjustierung

- Krankenhausvergleich

constant risk fallacy

Institut

School of health

and Related research,

University of Sheffield

England

Bibliografie

DOI 10.1055/s-0031-1286095

Dtsch Med Wochenschr 2011;

136: S66 - (c) Georg Thieme Ver-

lag KG Stuttgart - New York .

ISSN 0012-0472

Korrespondenz

\section{Prof. Jon Nicholl, DSC}

Dean, School of health and

Related research

University of Sheffield

Western Bank

Sheffield S10 2TN

England
Comparisons of health outcomes between people, services, institutions, and populations are used to assess the relative quality of health care. However, these non-experimental comparisons may be confounded by differences in casemix factors associated with the outcome. Casemix adjustment is used to create a fair comparison but does it? Simulation experiments suggest that casemix adjustment can make the bias worse in non-experimental studies. How is this possible? This talk will explore the problem that casemix variables may have a different effect in different populations - this is the constant risk fallacy. Examples of non-constant risk in hospital comparisons will be presented and possible solutions will be explored. 